\title{
INFLUENCE OF METALLIC CONTACTS ON THE DEMBER EMF IN BIPOLAR SEMICONDUCTORS*
}

\author{
A. Konin \\ Semiconductor Physics Institute, A. Goštauto 11, LT-01108 Vilnius, Lithuania \\ E-mail: konin@spi.pfi.lt
}

Received 14 September 2005

\begin{abstract}
A theory of the Dember effect in bipolar semiconductors accounting for the boundary conditions in a metal-semiconductor contact and distortion of energy bands near semiconductor surface is presented. It is shown that the Dember electromotive force (emf) depends on the surface potential and the Dember emf is negative for flat energy bands.
\end{abstract}

Keywords: Dember electromotive force (emf), equilibrium built-in electric field, diffusion-recombination (DR) mode, screening $(\mathrm{S})$ mode

PACS: $72.40 .+\mathrm{W}$

\section{Introduction}

The Dember effect is the emf arising in a semiconductor sample steadily absorbing light at one surface. The quasi-neutrality approximation was assumed in most of previous theories of the Dember effect $[1,2]$. To our knowledge, only paper [3] is aimed at the calculation of the Dember emf taking into account the bulk charge. It was assumed in [3] that illuminated sample surface is in contact with a dielectric (gas or vacuum). However, usually emf is measured across the metallic contacts placed on illuminated and dark surfaces of semiconductor sample. A metallic contact changes boundary conditions (BCs) on the illuminated surface: photoinduced electrons can move from semiconductor into metal. Therefore the charge density should increase near illuminated surface and the Dember emf should decrease. The distortion of energy bands [4] creates the equilibrium built-in electric field. This field affects the photoinduced charge density and so changes the Dember emf value.

This article is aimed at the development of the theory of the Dember effect in bipolar semiconductors.

\section{Theory}

Let us consider a bipolar semiconductor plate $0 \leq$ $x \leq L$ with the surface at $x=0$ illuminated by

* The report presented at the 36th Lithuanian National Physics Conference, 16-18 June 2005, Vilnius, Lithuania. strongly absorbed light. The thickness of the sample $L$ essentially exceeds the diffusion length (see below). Semiconductor contains a shallow donor level, which is completely depleted. A semi-transparent metallic contact is placed on the surface $x=0$ of the sample and the grounded metallic contact is placed on the surface $x=L$. We suppose that light wavelength corresponds to the region of fundamental absorption and that photoexcitation is weak.

The densities of electrons $n$ and holes $p$, as well as the electric potential $\varphi$, are obtained from solution of the continuity equations $[3,5]$ and the Poisson equation

$$
\begin{aligned}
& \frac{1}{e} \frac{\mathrm{d} j_{n}}{\mathrm{~d} x}-\frac{\delta n}{\tau_{n}}-\frac{\delta p}{\tau_{p}}=0, \\
& \frac{1}{e} \frac{\mathrm{d} j_{p}}{\mathrm{~d} x}+\frac{\delta n}{\tau_{n}}+\frac{\delta p}{\tau_{p}}=0, \\
& \frac{\mathrm{d}^{2} \varphi}{\mathrm{d} x^{2}}=\frac{e}{\varepsilon \varepsilon_{0}}\left(n-n_{0}-p+p_{0}\right),
\end{aligned}
$$

where $-e$ is the electron charge,

$$
\begin{aligned}
& j_{n}=-e n \mu_{n} \frac{\mathrm{d} \varphi}{\mathrm{d} x}+\mu_{n} k T \frac{\mathrm{d} n}{\mathrm{~d} x}, \\
& j_{p}=-e p \mu_{p} \frac{\mathrm{d} \varphi}{\mathrm{d} x}-\mu_{p} k T \frac{\mathrm{d} p}{\mathrm{~d} x}
\end{aligned}
$$

are the electron and hole current densities [4], $\tau_{n(p)}$ is the time characterising the electron (hole) bulk recombination rate [5], $\delta n(\delta p)$ is the non-equilibrium density 
of electrons (holes), $n_{0}\left(p_{0}\right)$ is the equilibrium density of electrons (holes) in the bulk of the sample, $\varepsilon$ is the semiconductor electrical permittivity, $\varepsilon_{0}$ is the vacuum permittivity, $\mu_{n(p)}$ is the electron (hole) mobility, $k$ is the Boltzmann constant, and $T$ is the temperature of the semiconductor.

The densities of carriers and electric potential can be expressed as

$$
\begin{gathered}
n(x)=n_{\mathrm{eq}}(x)+\delta n(x), \\
p(x)=p_{\mathrm{eq}}(x)+\delta p(x), \\
\varphi(x)=\varphi_{\mathrm{eq}}(x)+\delta \varphi(x),
\end{gathered}
$$

where $n_{\text {eq }}(x)$ and $p_{\text {eq }}(x)$ are the equilibrium densities of electrons and holes, $\varphi_{\text {eq }}(x)$ is the equilibrium electric potential, and $\delta \varphi(x)$ is the non-equilibrium electric potential.

The equilibrium densities and potential for special cases are obtained in [6].

The Poisson Eq. (3) for non-equilibrium values $\delta n$, $\delta p$, and $\delta \varphi$ takes the form

$$
\frac{\mathrm{d}^{2} \varphi}{\mathrm{d} x^{2}}=\frac{e}{\varepsilon \varepsilon_{0}}(\delta n-\delta p) .
$$

Since photoexcitation is weak, we can expand the expressions of partial currents in series by small parameters $\delta n / n_{0} \ll 1, \delta p / p_{0} \ll 1$, and $\delta \varphi \ll k T / e$. In linear approximation we derive from Eqs. (4)

$$
\begin{aligned}
& \frac{1}{e} j_{n}=-\mu_{n} n_{\mathrm{eq}} \frac{\mathrm{d} \delta \varphi}{\mathrm{d} x}-\mu_{n} \delta n \frac{\mathrm{d} \varphi_{\mathrm{eq}}}{\mathrm{d} x}+\frac{\mu_{n} k T}{e} \frac{\mathrm{d} \delta n}{\mathrm{~d} x}, \\
& \frac{1}{e} j_{p}=-\mu_{p} p_{\mathrm{eq}} \frac{\mathrm{d} \delta \varphi}{\mathrm{d} x}-\mu_{p} \delta p \frac{\mathrm{d} \varphi_{\mathrm{eq}}}{\mathrm{d} x}-\frac{\mu_{p} k T}{e} \frac{\mathrm{d} \delta p}{\mathrm{~d} x} .
\end{aligned}
$$

The BCs can be obtained on the basis of results of [7]:

$$
\begin{aligned}
\left.\frac{1}{e} j_{p}\right|_{x=0} & =-\left.v \delta p\right|_{x=0}+G, \\
\left.\delta n\right|_{x=0} & =0, \\
\left.\delta \varphi_{M}\right|_{x=0} & =\left.\delta \varphi\right|_{x=0},
\end{aligned}
$$

where $v$ is the illuminated surface recombination rate (SRR), $G$ is the electron-hole pairs generation rate per unit illuminated surface area, and $\delta \varphi_{M}$ is the variation of electric potential of metallic contact.

Taking into consideration that the diffusion length significantly exceeds the Debye length we obtain the solution of Eqs. (1), (2), and (6) as a sum of two modes [3]: diffusion-recombination (DR) mode and screening
(S) mode. These modes are denoted by subscripts $\mathrm{R}$ and $\mathrm{S}$ accordingly:

$$
\begin{gathered}
\delta n=\delta n_{\mathrm{R}}+\delta n_{\mathrm{S}}, \\
\delta p=\delta p_{\mathrm{R}}+\delta p_{\mathrm{S}}, \\
\delta \varphi=\delta \varphi_{\mathrm{R}}+\delta \varphi_{\mathrm{S}}
\end{gathered}
$$

DR mode is obtained from the solution of Eqs. (1), (2), (6), and (7) with BC (8) and condition of quasineutrality $\left|\delta n_{\mathrm{R}}-\delta p_{\mathrm{R}}\right| \ll \delta n_{\mathrm{R}}$. Moreover, the equilibrium densities $n_{\text {eq }}, p_{\text {eq }}$ and potential $\varphi_{\text {eq }}$ depend on coordinate $x$ only in a thin layer of a thickness approximately equal to the Debye length. That is why for DR mode we can suppose that $n_{\text {eq }}=n_{0}, p_{\text {eq }}=p_{0}$, and $\varphi_{\text {eq }}=0$.

The continuity equations for $\mathrm{S}$ mode take the form

$$
\frac{\mathrm{d} j_{n \mathrm{~S}}}{\mathrm{~d} x}=0, \quad \frac{\mathrm{d} j_{n \mathrm{~S}}}{\mathrm{~d} x}=0 .
$$

Substituting the solution of Eq. (12) into Eq. (6) one gets for $\mathrm{S}$ mode

$$
\frac{\mathrm{d}^{2} \delta \varphi_{\mathrm{S}}}{\mathrm{d} x^{2}}=\frac{e^{2}}{\varepsilon \varepsilon_{0} k T}\left(n_{\mathrm{eq}}+p_{\mathrm{eq}}\right) \delta \varphi_{\mathrm{S}} .
$$

With the use of relations [4]

$$
\begin{aligned}
\frac{1}{e} j_{p} & =-D \frac{\mathrm{d} \delta p_{\mathrm{R}}}{\mathrm{d} x}, \\
\frac{\mathrm{d} \varphi_{\mathrm{eq}}}{\mathrm{d} x} & =\frac{k T}{e n_{\mathrm{eq}}} \frac{\mathrm{d} n_{\mathrm{eq}}}{\mathrm{d} x}=\frac{k T}{e p_{\mathrm{eq}}} \frac{\mathrm{d} p_{\mathrm{eq}}}{\mathrm{d} x}, \\
n_{\mathrm{eq}}(0) & =n_{0} \exp \left(\frac{e \varphi^{S}}{k T}\right), \\
p_{\text {eq }}(0) & =p_{0} \exp \left(-\frac{e \varphi^{S}}{k T}\right),
\end{aligned}
$$

and Eqs. (1), (2), (7 - 9), and (12) we derive

$$
\varphi_{\mathrm{D}}=\varphi_{\mathrm{D} 0} F_{v}-\frac{G \lambda}{D n_{0}} \frac{k T}{e} F_{v} \exp \left(-\frac{e \varphi^{S}}{k T}\right),
$$

where $\varphi_{\mathrm{D}}=\left.\delta \varphi_{\mathrm{M}}\right|_{x=0}$ is the Dember emf,

$$
\varphi_{\mathrm{D} 0}=\frac{G \lambda}{D} \frac{k T}{e} \frac{\mu_{n}-\mu_{p}}{n_{0} \mu_{n}+p_{0} \mu_{p}}
$$

is the classical Dember emf [6] at negligible SRR value,

$$
F_{v}=\left\{1+\left[1+\frac{p_{0} \exp \left[-2 e \varphi^{S} /(k T)\right]}{n_{0}}\right] \frac{v \tau}{\lambda}\right\}^{-1}
$$


is the factor determined by the SRR value, $\varphi^{S}$ is the surface potential (SP), and

$$
D=\frac{k T}{e} \frac{\left(n_{0}+p_{0}\right) \mu_{n} \mu_{p}}{n_{0} \mu_{n}+p_{0} \mu_{p}}
$$

is the bipolar diffusion coefficient.

When both SP and SRR are small $\left(\left|\varphi^{S}\right| \ll k T / e\right.$ and $v \ll \lambda / \tau$ ) the Dember emf is equal to

$$
\varphi_{\mathrm{D}}=\frac{G \lambda}{D n_{0}} \frac{k T}{e}\left[\frac{\mu_{p}\left(n_{0}+p_{0}\right)}{n_{0} \mu_{n}+p_{0} \mu_{p}}-\frac{e \varphi^{S}}{k T}\right] .
$$

The expressions of DR mode and $\mathrm{S}$ mode at small SP take the form

$$
\begin{aligned}
\delta n_{\mathrm{R}} & =\frac{G \lambda}{D} F_{v} \exp \left(-\frac{x}{\lambda}\right) \\
\delta p_{\mathrm{R}} & =\frac{G \lambda}{D} F_{v}(1-\beta) \exp \left(-\frac{x}{\lambda}\right) \\
\delta \varphi_{\mathrm{R}} & =\frac{D \lambda}{G} F_{v} \frac{k T}{e} \frac{\mu_{n}-\mu_{p}}{n_{0} \mu_{n}+p_{0} \mu_{p}} \\
& \times \exp \left(-\frac{x}{\lambda}\right) \\
\delta n_{\mathrm{S}} & =-\left[1-\alpha+\alpha \exp \left(-\frac{x}{r_{\mathrm{D}}}\right)\right] \\
& \times \frac{G \lambda}{D} F_{v} \exp \left(-\frac{x}{r_{\mathrm{D}}}\right) \\
\delta p_{\mathrm{S}} & =\left[1-\alpha-\left(\alpha-\frac{2 e \varphi^{S}}{k T}\right) \exp \left(-\frac{x}{r_{\mathrm{D}}}\right)\right] \\
& \times \frac{G \lambda}{D} \frac{p_{0}}{n_{0}} F_{v} \exp \left(-\frac{x}{r_{\mathrm{D}}}\right) \\
\delta \varphi_{\mathrm{S}} & =-\left[1-\alpha+\left(\alpha-\frac{e \varphi^{S}}{k T}\right) \exp \left(-\frac{x}{r_{\mathrm{D}}}\right)\right] \\
& \times \frac{G \lambda}{D n_{0}} \frac{k T}{e} F_{v} \exp \left(-\frac{x}{r_{\mathrm{D}}}\right)
\end{aligned}
$$

where

$$
\lambda=\sqrt{D \frac{\tau_{n} \tau_{p}}{\tau_{n}+\tau_{p}}}
$$

is the diffusion length,

$$
\beta=\frac{\mu_{n}-\mu_{p}}{n_{0} \mu_{n}+p_{0} \mu_{p}} \frac{\varepsilon \varepsilon_{0} k T}{\lambda^{2} e^{2}}, \quad r_{\mathrm{D}}=\sqrt{\frac{\varepsilon \varepsilon_{0} k T}{e^{2}\left(n_{0}+p_{0}\right)}}
$$

is the Debye length, and

$$
\alpha=\frac{4 n_{0}+2 p_{0}}{3\left(n_{0}+p_{0}\right)} \frac{e \varphi^{S}}{k T} .
$$

In conclusion, for convenient comparison we present the results of [3]:

$$
\begin{gathered}
\delta \varphi_{[3]}=\varphi_{\mathrm{D} 0}\left[\exp \left(-\frac{x}{\lambda}\right)-\frac{r_{\mathrm{D}}}{x} \exp \left(-\frac{x}{r_{\mathrm{D}}}\right)\right], \\
\delta \varphi_{[3] \mathrm{Dem}}=\varphi_{\mathrm{D} 0}\left[1-\frac{r_{\mathrm{D}}}{\lambda}\right] .
\end{gathered}
$$

\section{Discussion of results}

It can be seen that presented expression for DR mode (see Eq. (17)) coincides with that obtained in [3] in the case of negligible SRR. The $\mathrm{S}$ mode expressions (Eqs. (18) and (19)) differ from those obtained in [3] by amplitude and analytical dependence on coordinate $x$. There are two sources of these differences: (i) unlike [3], in our case the electrons can cross the metalsemiconductor contact and (ii) the distortion of energy bands influences the non-equilibrium carriers movement near illuminated surface.

As follows from Eq. (15) the Dember emf is negative when the SP is equal to zero $\left(\varphi^{S}=0\right)$. In this case a part of photoinduced electrons moves from semiconductor into metallic contact (see Eqs. (16) and (18)). This leads to the growth of S mode charge density (as compared with [3]) and results in the decrease of electric potential of illuminated surface (the Dember emf).

When the SP is positive $\left(\varphi^{S}>0\right)$ the built-in electric field $E_{\text {eq }}=-\mathrm{d} \varphi_{\text {eq }} / \mathrm{d} x$ arises in semiconductor sample. The $E_{\text {eq }}$ is directed from the illuminated surface into the bulk of semiconductor $\left(E_{\text {eq }}>0\right)$. It causes the $\mathrm{S}$ mode hole density reduction and the $\mathrm{S}$ mode electron density increase (see Eq. (18)) as compared with the case of $\varphi^{S}=0$. The $\mathrm{S}$ mode charge density grows and therefore the Dember emf decreases. Note that the $\mathrm{S}$ mode electron density on the surface $x=0$ depends only on the DR mode electron density, i. e. $\delta n_{\mathrm{S}}(0)=-\delta n_{\mathrm{R}}(0)$. The $\mathrm{S}$ mode electron density is negative independently of the SP value (the nonequilibrium electron density $\delta n$ is positive). At large SP values $\left(\varphi^{S} \gg k T / e\right)$ we obtain $\delta p_{\mathrm{S}} \rightarrow \delta n_{\mathrm{S}}$, i.e. the $S$ mode charge density tends to zero. In this case the Dember emf is determined by the DR mode and is equal to its classical value.

When the SP is negative $\left(\varphi^{S}<0\right.$ and $\left.E_{\text {eq }}<0\right)$ the $\mathrm{S}$ mode electron density decreases and the $\mathrm{S}$ mode hole density grows as compared with the case of $\varphi^{S}=0$. The $\mathrm{S}$ mode charge density growth reduces the Dember emf (see Eq. (18)). For $\varphi^{S}<0$ (unlike the case of $\varphi^{S}>0$ considered above) the $\mathrm{S}$ mode hole density is 


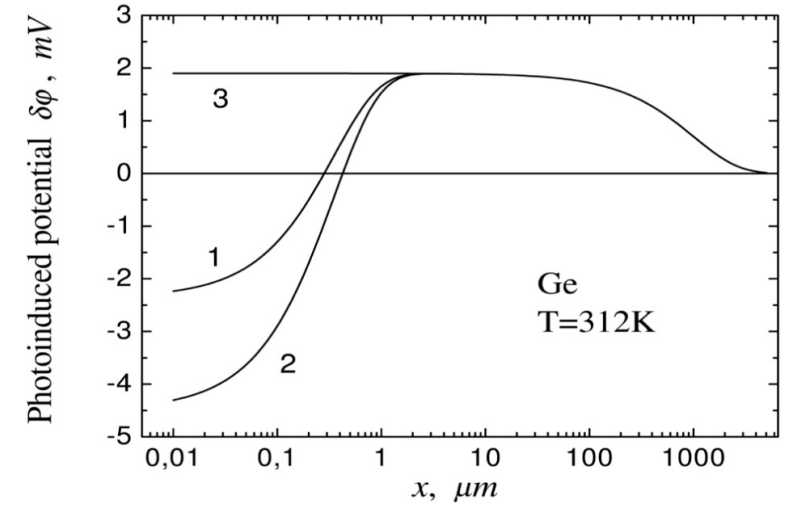

Fig. 1. Photoinduced electric potential distribution in Ge for some SP values: 1 for $\varphi^{S}=5.4 \mathrm{mV}, 2$ for $\varphi^{S}=-5.4 \mathrm{mV}$. Line 3 gives the $\delta \varphi$ distribution from [3].

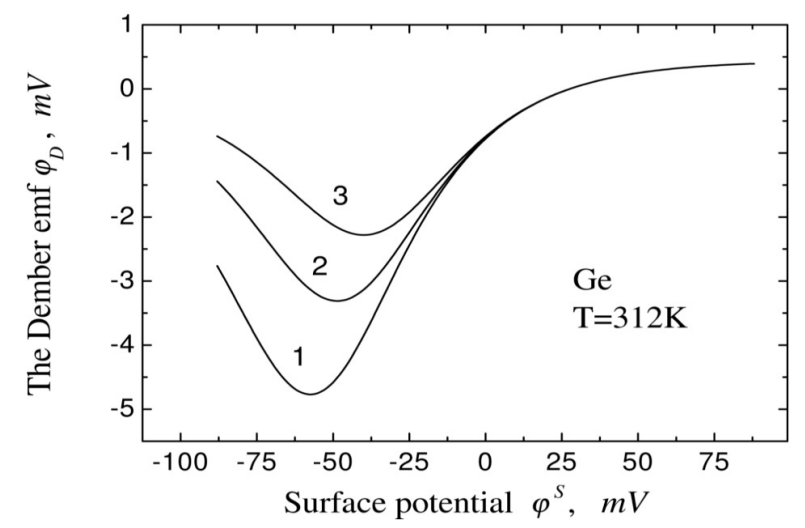

Fig. 2. Dember emf dependence on SP for some SRR values: 1 for $v=10 \mathrm{~cm} / \mathrm{s}, 2$ for $v=20 \mathrm{~cm} / \mathrm{s}, 3$ for $v=40 \mathrm{~cm} / \mathrm{s}\left(\varphi_{\mathrm{D} 0}=0.44 \mathrm{mV}\right)$.

limited only by the SRR value and the condition $\delta p_{\mathrm{S}} \ll$ $p_{0}$ assumed in theory. Therefore (see Eq. (14)) the $\left|\varphi_{\mathrm{D}}\right|$ exceeds its classical value when $\left(-\varphi^{\mathrm{S}}\right) \gg k T / e$ and $v \ll \lambda / \tau$.

The distribution of photoinduced electric potential in pure $\mathrm{Ge}\left(T=312 \mathrm{~K}, \lambda=0.1 \mathrm{~cm}, \mu_{n}=3800 \mathrm{~cm}^{2} /(\mathrm{V} \cdot \mathrm{s})\right.$, $\mu_{p}=1800 \mathrm{~cm}^{2} /(\mathrm{V} \cdot \mathrm{s}), r_{\mathrm{D}}=3.5 \cdot 10^{-5} \mathrm{~cm}, G=$ $1.3 \cdot 10^{16} \mathrm{~cm}^{-2} \cdot \mathrm{s}^{-1}$ ) for SRR $v=20 \mathrm{~cm} / \mathrm{s}$ is shown in Fig. 1. It is seen that electric potential distribution in the region $x=(0-1) \mu \mathrm{m}$ is determined mainly by $\mathrm{S}$ mode. The Dember emf is negative and its modulus decrease when the SP increases. Curve 3 represents the photoinduced electric potential from [3], which in our case coincides with the classical potential distribution $\delta \varphi_{\mathrm{R}}(x)$.

The Dember emf dependence on the SP in pure Ge $\left(G=3 \cdot 10^{15} \mathrm{~cm}^{-2} \cdot \mathrm{s}^{-1}\right.$ and the other parameters are the same as in Fig. 1) for some SRR values is shown in Fig. 2. As it is seen from Fig. 2, the Dember emf has a $\operatorname{minimum} \varphi_{\mathrm{D} \min }$ at $\varphi^{S}=[k T /(2 e)] \log \left[v \tau p_{0} /\left(\lambda n_{0}\right)\right]$. The $\varphi_{\mathrm{D} \text { min }}$ strongly depends on SRR value $v$.

\section{Conclusions}

The theory of the Dember effect accounting for the boundary conditions in a metal-semiconductor contact as well as the distortion of energy bands near semiconductor surface has been developed. It is shown that the Dember emf essentially depends on the surface potential. The Dember emf is negative in the case of flat energy bands.

\section{References}

[1] L. Kronik and Y. Shapira, Surf. Sci. Rep. 37, 1 (1999).

[2] J.N. Chazalviel, Coulomb Screening by Mobile Charges (Birkhäuser, Boston, 1999).

[3] M. Krčmar and W.M. Saslow, Phys. Rev. B 65, 233313 (1-4) (2002).

[4] V.L. Bonch-Bruevich and S.G. Kalashnikov, Fizika Poluprovodnikov (Nauka, Moscow, 1977) [Physics of Semiconductors, in Russian].

[5] I.N. Volovichev and Yu.G. Gurevich, Semiconductors 35, 306-314 (2001).

[6] P.S. Kireev, Fizika Poluprovodnikov (Vysshaya Shkola, Moscow, 1975) [Semiconductor Physics, in Russian].

[7] O.Yu. Titov, J. Giraldo, and Yu.G. Gurevich, Appl. Phys. Lett. 80, 3108-3110 (2002).

\title{
METALINIU KONTAKTU ITAKA DEMBERIO ELEKTROVARAI BIPOLINIUOSE PUSLAIDININKIUOSE
}

\author{
A. Konin
}

Puslaidininkiu fizikos institutas, Vilnius, Lietuva

\section{Santrauka}

Darbe pateikiama Demberio elektrovaros (EV) teorija, kurioje atsižvelgta i kraštines sąlygas metalo-puslaidininkio sandūroje ir energijos zonų iškrypimą puslaidininkio paviršiuje. Parodyta, kad Demberio EV iš esmès priklauso nuo paviršiaus elektrinio potencialo, kuris nulemia energijos zonų iškrypimą. Plokščiu energijos zonu atveju Demberio EV yra neigiama. 